\title{
Incorporating genetic biomarkers into predictive models of normal tissue toxicity
}

\author{
Gillian C Barnett ${ }^{1 *}$, Sarah L Kerns ${ }^{2 *}$, David J Noble ${ }^{1}$, Alison M Dunning ${ }^{3}$ \\ Catharine ML West ${ }^{4}$, Neil G Burnet ${ }^{5}$
}

1. Oncology Centre, Addenbrooke's Hospital, Cambridge University Hospitals NHS Foundation Trust, Hills Road, Cambridge, CB2 0QQ, UK.

2. Rubin Center for Cancer Survivorship, Department of Radiation Oncology, University of Rochester Medical Center, Rochester, NY, USA.

3. Centre for Cancer Genetic Epidemiology, Department of Oncology, University of Cambridge, Strangeways Research Laboratory, Cambridge, CB1 8RN, UK.

4. Institute of Cancer Sciences, University of Manchester, Manchester Academic Health Science Centre, Christie Hospital, Manchester, UK.

5. University of Cambridge Department of Oncology, Cambridge Biomedical Campus, Addenbrooke's Hospital, Hills Road, Cambridge, CB2 0QQ, UK.

* Indicates joint first authors

Author for correspondence: Dr Gillian G Barnett

Phone: $01223336800 \quad$ Fax: 01223763120

Email: gillian.barnett@addenbrookes.nhs.uk and ngb21@cam.ac.uk

Word Count $\quad 3738$

Number of tables $\quad 1$

Number of figures $\quad 3$ 


\begin{abstract}
There is considerable variation in the level of toxicity patients experience for a given dose of radiotherapy that is associated with differences in underlying individual normal tissue radiosensitivity. A number of syndromes have a large effect on clinical radiosensitivity, but these are rare. Amongst non-syndromic patients, variation is less extreme, but equivalent to a $\pm 20 \%$ variation in dose. Thus, if individual normal tissue radiosensitivity could be measured, it should be possible to optimise schedules for individual patients. Early investigations of in vitro cellular radiosensitivity supported a link with tissue response, but individual studies were equivocal. A lymphocyte apoptosis assay has potential, and is currently under prospective validation. The investigation of underlying genetic variation also has potential. Although early candidate gene studies were inconclusive, more recent genome wide association studies (GWAS) are revealing definite associations between genotype and toxicity and highlighting the potential for future genetic testing. Genetic testing and individualised dose prescriptions could reduce toxicity in radiosensitive patients, and permit isotoxic dose escalation to increase local control in radioresistant individuals. The approach could improve outcomes for half of the patients requiring radical radiotherapy. As a number of patient- and treatment-related factors also affect risk of toxicity for a given dose, genetic testing data will need to be incorporated into models that combine patient, treatment and genetic data.
\end{abstract}

Keywords: GWAS, SNP, normal tissue, radiosensitivity, radiotherapy 


\section{Introduction}

Radiotherapy (RT) is one of the most effective treatments for cancer [1]. It is needed in the care of $\sim 50 \%$ of cancer patients at some time in their illness. As the lifetime risk of cancer for people born since 1960 is estimated to be $>50 \%$ [2], RT will ultimately be required for a quarter of the population. It forms a major part of the treatment plan for $40 \%$ of those who are cured and is primarily responsible for cure in $16 \%$. Around $60 \%$ of patients undergoing $\mathrm{RT}$ are treated with curative intent [3]. The incidence of cancer in the UK is $\sim 331,000$ cases per annum [4], so that radical RT is used in around 100,000 patients each year.

The success of RT in eradicating a tumour depends especially on radiation dose, which is limited by the tolerance of surrounding normal tissues. Patients treated to the same curative dose vary in the toxicity they experience. A minority have no observable effect, most have clinically mild or moderate changes, and a few suffer serious normal tissue complications that may even be life-threatening. The incidence and severity of normal tissue damage is radiation dose dependent. However, even mild or moderate damage can have a substantial negative impact on patient-reported quality of life, and requires consideration. Selection of the appropriate RT is based on a balance between lowering the dose to keep the incidence of severe normal tissue complications at an acceptably low level, and raising the dose to increase the probability of local control. However, at present, this is done only on a population level, without the possibility of personalisation based on individual normal tissue tolerance.

Toxicity can be reduced by using advanced RT techniques which limit normal tissue doses, especially intensity modulated radiotherapy (IMRT) [5-13], addressing physical individualisation. All modern RT includes a substantial component of physical individualisation, which is not yet matched by the biological equivalent. Developments in RT, including the ability to combine physical and biological individualisation, will make an essential contribution to the Cancer Research UK vision of curing $75 \%$ of cancer patients in 20 years' time [14]. This article addresses the issue of biological individualisation of RT, which is a goal which should be reached well within this time frame, offering better cure rates with less toxicity for patients with cancer. 


\section{Background}

\section{The first descriptions of individual variation in toxicity}

The first documented illustration of variation in toxicity following RT was reported by Holthusen in 1936 [15]. The evidence for individual variation in radiosensitivity led to the development of studies aimed at measuring radiosensitivity to predict a cancer patient's risk of toxicity. The variation was hypothesised to have a genetic basis, even though these efforts pre-dated the development of the necessary genotyping technology to prove this. Initially laboratory measurements of radiosensitivity were developed to attempt to predict normal tissue toxicity. The earliest studies focused on individuals with very severe toxicity, many with heritable syndromes, including ataxia telangiectasia (AT). Fibroblasts cultured from skin samples of such patients were shown to be unusually radiosensitive using clonogenic assays [16-21]. Clonogenic assays assess reproductive integrity, i.e., ability of single cells to form a colony with a minimum of 50 cells (representing at least 5-6 cell divisions) [22]. These studies showed a wide range of sensitivity, largely because of the inclusion of cells from patients with genetic syndromes typically associated with DNA damage recognition and repair defects, causing severe clinical and cellular radiosensitivity,

\section{Efforts to develop predictive testing based on cellular radiosensitivity}

With the demonstration in the 1980s that there was variation in fibroblast radiosensitivity between cells cultured from individuals both with and without known genetic syndromes [17, 23-25], studies were set up to investigate the relationship between cellular and clinical radiosensitivity with a goal of developing a test to predict a patient's likely reaction to RT. The first studies were retrospective and compared patients who developed severe reactions to RT to those with no/minimal toxicity. Toxicity was typically relative, with some patients probably not expressing really severe reactions, which presented a problem of discrimination in the clonogenic assay. The results suggested some value in cellular sensitivity testing, but without providing clear proof of a link between cellular and tissue radiosensitivity.

The next step saw several small studies of patients whose toxicity had been quantified more objectively. Each of these showed a correlation between cellular sensitivity and normal tissue response [26-29]. Although the results, individually and collectively, were encouraging, the relationship between cellular sensitivity and normal tissue response could 
not be replicated in larger studies using the clonogenic assay with fibroblast cultured from skin samples [30]. Better results were obtained using lymphocytes [31].

Since deriving fibroblast lines from skin samples and performing the necessary clonogenic assays (in triplicate) takes 6-8 weeks and is labour-intensive, interest moved to investigating more rapid assays that would have greater clinical utility. The main ones studied have been expertly reviewed elsewhere [32], and include: chromosome damage assays, including include the 'micronucleus' and G2 lymphocyte assays; DNA damage, including the 'comet' assay; assessment of apoptosis; the ability of fibroblast to undergo radiation-induced differentiation; and alteration in telomere length. Combinations of assays have also been tested. Despite considerable effort, none of these methods proved reliable in a clinical setting. An important reason may be that the differences between cells from normal (as opposed to syndromic) patients are rather small, and of similar magnitude to the variability in the assays. Another important reason may be that the response of cultured cells might not be sufficiently comparable to the response of whole tissues, in which the microenvironment could play an important role in radiation-induced damage. Finally, the quality of dosimetry and reporting of clinical toxicity must be well controlled, but in general studies seeking to correlate sensitivity assays with clinical outcome have addressed these issues.

There is also interest in measuring the expression of cytokines in serum/plasma. A combined two centres' analysis of 165 patients with non-small cell lung cancer showed that elevation of and plasma transforming growth factor (TGF)- $\beta 1$ during RT predicted for lung toxicity [33]. However, despite early reports of a correlation [33-35], not all studies have demonstrated a relationship [36], and more work is certainly required [37].

Studies have also attempted to derive gene expression signatures [38-41]. This work is challenging when attempting to measure radiosensitivity due to the need to choose whether to investigate baseline gene expression or radiation-induced expression, and has not yet been fruitful.

A single exception, the lymphocyte apoptosis assay, has emerged which appears to have potential [42]. Lymphocytes from patients with a variety of cancers who experienced severe late RT reactions, exhibited an impaired in vitro apoptotic response after 8Gy. For 348 patients evaluated at 2 years, or who developed a grade $\geq 2$ toxicity before that, the area under 
the receiver-operating characteristic curve was 0.83 (95\% CI, 0.78-0.87), and the negative predictive value for grade 3 toxicity was $98.5 \%$. At this level of prediction, it might be possible to undertake modest dose escalation. It is still unclear whether it can be used as a clinical predictive test, but it is currently being further evaluated [43].

\section{Challenges with radiosensitivity assays}

There are several problems associated with research aimed at testing whether laboratory measurement of radiosensitivity predict clinical radiosensitivity. First, assays are not standardised and there have been few attempts to ensure transferability across laboratories. Second, the studies involve different radiation doses, dose rates, and assay conditions. Third, patient cohorts are heterogeneous. Some studies involved severe atypical reactions, others investigated unselected patients. The factors determining radiosensitivity might differ between these two groups. Fourth, study designs vary considerably and few involve power calculations and multivariate analyses. Fifth, reproducibility is rarely reported but cell based assays tend to have a large experimental variability relative to inter-individual variability in radiosensitivity. Progress in the area requires standardised approaches for measuring radiosensitivity which are transferable across laboratories, and the establishment of guidelines for carrying out studies.

\section{Challenges with clinical studies}

A key challenge in clinical studies is to control for other factors which affect toxicity (Table 1). The main recognised determinants of radiotherapy toxicity relate to physics (radiation dose, dose rate, dosimetry, dose inhomogeneity, treatment volume), treatment (interaction with other modalities such as surgery, chemotherapy, hormone therapy, medication such as statins), patient factors (age, haemoglobin, smoking, co-morbid conditions such as diabetes \& collagen vascular disease) and genetics [32]. Other factors which have been hypothesised but not confirmed to influence clinical radiosensitivity include sex, ethnicity, body mass index, diet, and alcohol consumption.

\section{Genetic variation influences clinical radiosensitivity}

Several clinical studies have shown that inter-patient variability in toxicity amongst nonsyndromic patients receiving RT is greater than intra-patient variability and some have 
suggested that, after controlling for other factors, the genetic component could be as high as $80 \%$ [44-46].

Heritability is defined as the proportion of phenotypic variance in a population attributable to additive genetic factors. Heritability of a disease is usually demonstrated by studies comparing phenotypic variance between twins or wider family members. However, evidence of heritability of RT toxicity is difficult to obtain due to the need for prospective toxicity data collection in cancer survivors and their close family. Thus, there is limited literature on the heritability of radiation toxicity. Scott et al. used a chromosome damage assay to investigate the radiosensitivity of first-degree relatives of 16 sensitive and eight 'normal' breast cancer survivors [47]. Sixty-two percent of first-degree relatives of sensitive patients were also radiosensitive compared with 7\% first-degree relatives of 'normal' patients [48]. Unfortunately, this assay did not transfer well between laboratories, but recent studies of in vitro cellular radiosensitivity have suggested estimates of heritability of between $60 \%$ and $80 \%$ [48-53].

Syndromes associated with clinical radiosensitivity include AT [16], individuals with LIG4syndrome [54], and individuals with Nijmegen Breakage Syndrome [55] involving ATM, $L I G 4$, and NBN respectively. Such radiosensitivity syndromes illustrate that specific genes influence clinical radiosensitivity. These syndromes, characterised by Mendelian inheritance of germ-line mutations in genes involved in the detection of DNA damage or DNA repair (the DNA damage response, DDR), result in genomic instability and cancer pre-disposition. These syndromes are rare and probably of little relevance when assessing radiosensitivity in most cancer patients undergoing RT.

\section{Radiogenomics}

\section{Candidate gene studies}

Current understanding is that radiosensitivity is an inherited polygenic trait, dependent on the interaction of many genes/gene products involved in multiple cell processes $[32,56,57]$. One way to study common genetic variation is to use single nucleotide polymorphisms (SNPs). Most SNP association studies of RT toxicity, published to date, have used a candidate gene approach in which a set of SNPs are selected on the basis of a hypothesized effect on one or more genes whose protein products are involved in cellular pathways known to be involved 
in radiation response. For example, radiation-induced cell killing, for which DNA damage is a major mechanism, is thought to be a triggering event in the development of RT toxicity. Additionally, the release of cytokines is considered to initiate biological responses in multiple cell types leading to the development of late toxicity. The focus of candidate gene studies has thus been on genes involved in DNA damage recognition and repair (e.g. ATM, BRCA1, BRCA2 and TP53), free radical scavenging (e.g. SOD2) and anti-inflammatory response (e.g. $T G F B 1$ ). Most studies, reviewed elsewhere [56, 58, 59], have been underpowered, including fewer than 500 samples. The studies tested many SNPs without adjusting for multiple comparisons and, although many reported positive associations, findings have proved difficult to replicate. One exception is a candidate gene study of 2036 women whose toxicity was scored after RT for breast cancer, which included a validation cohort to confirm the findings, and suggested a link between variation near the tumour necrosis factor alpha (TNF$\alpha)$ gene and toxicity [60].

In contrast, a large independent validation study of the SNPs studied in candidate genes did not replicate previously reported late-toxicity associations, suggesting that the hypothesis that published SNPs individually exert a clinically significant effect could be excluded [61]. In addition, the international Radiogenomics Consortium collected and analysed individual patient level data from both published and unpublished studies of SNPs in TGFB1, encoding the pro-fibrotic cytokine TGF- $\beta 1$. In this meta-analysis of 2782 patients from 11 cohorts, no statistically significant associations between either fibrosis or overall toxicity and rs1800469 genotype were observed [62].

These results overall demonstrate the difficulty of using small candidate gene studies, which presupposed that the biology of normal tissue toxicity is comprehensively understood. A different approach was needed, which was not subject to this limitation, namely genome wide association studies (GWAS).

\section{Genome wide association studies (GWAS) in Radiogenomics}

With the rapid reduction in cost of genotyping came the possibility of carrying out GWAS to identify new genes associated with toxicity, with no a priori assumptions about which genes might be important. The first published radiogenomics GWAS was a small pilot study among African American men treated with RT for prostate cancer. SNP rs2268363 within the FSHR 
(follicle-stimulating hormone receptor) gene, involved in testes development and spermatogenesis) was associated with erectile dysfunction at a genome-wide level of statistical significance $\left(\mathrm{p}=5.5 \times 10^{-8}\right)[63]$.

Following this encouraging result, three larger radiogenomics GWAS have been undertaken and have uncovered additional risk loci at similarly appropriate levels of significance. In one, an association was found with late rectal bleeding following prostate cancer radiotherapy which approached genome-wide significance [64]. Of note, most of these early-identified SNP associations have been specific for toxicity in a particular tissue (for example rectal bleeding [64]). This suggestion that SNP associations can be specific to particular tissue types has been backed up by other studies.

A GWAS of late toxicity, incorporating both prostate and breast radiotherapy patients and using the STAT score of overall toxicity [65], identified a greater number of SNPs than expected by chance at a nominal significance level (Figs 1 \& 2), although no individual SNP reached the accepted threshold for genome-wide significance [66]. This study provided important evidence that there are likely to be many SNPs truly associated with late radiotherapy effects that will be uncovered by adequately powered studies of increased sample size.

A third GWAS has identified a putative locus on chromosome $2 \mathrm{q} 24.1$, within the TANC1 gene, associated with overall toxicity (a measure encompassing both urinary and rectal effects) following radiotherapy for prostate cancer (p-value 4.6 $\times 10^{-11}$ [67].

It is interesting that the putative loci reported so far are not close to obvious radiationassociated candidate genes, which is consistent with current opinion that we have insufficient understanding of the molecular pathogenesis of RT toxicity as a polygenic phenotype. Information from GWAS of other phenotypes suggest the allelic architecture underlying radiosensitivity will include a spectrum ranging from rare, highly penetrant to low-risk common alterations [68].

The increasing recognition that GWAS must include tens or even hundreds of thousands of patients $[56,57,68]$ led to the establishment of a Radiogenomics Consortium (RGC) in 2009 [69]. The consortium created a vital link between existing collaborative groups $[64,66,70$ - 
73]. The consortium provides a route for: sharing expertise and quality assurance procedures; developing best practices for data collection; pooling data; and carrying out replication studies, which are so necessary given the small sample sizes available in the constituent studies of the consortium. The RGC recently published the STROGAR guidelines [74], aimed at improving the quality, transparency and completeness of radiogenomics research reporting. The Radiogenomics Consortium has also provided a platform for conducting a meta-analysis of four GWAS of late effects from prostate cancer radiotherapy, including the three aforementioned studies. This is the most statistically powerful radiogenomics GWAS to date, including over 1,600 men treated with radiotherapy for prostate cancer. Additional efforts are underway to perform GWAS meta-analyses among breast cancer and head and neck cancer radiotherapy patients.

Sample sizes available within the RGC remain small by comparison with other GWAS consortia. Consequently, not all the currently reported putative radiotoxicity associations are likely to be replicated. Moreover, the reported loci do not yet explain sufficient variability in toxicity to be useful for the long-term goal of predictive SNP profiling. For comparison, consortia formed to identify breast and prostate cancer risk loci (BCAC:

http://apps.ccge.medschl.cam.ac.uk/consortia/bcac/; PRACTICAL:

http://practical.ccge.medschl.cam.ac.uk ) now have sample sizes in the order of 100,000 enabling them each to confirm almost 100 common genetic risk loci. The difference in risk of breast cancer between women at the very top and bottom of the SNP risk-profile developed from these loci is roughly 10 fold [75]. Sample sizes available within the RGC will continue to expand, allowing discovery and confirmation of further novel risk loci, and ultimately SNP risk-profiles for RT toxicity.

Many other challenges remain in radiogenomics that are related to heterogeneity in RT schedules between centres and countries; variable recording of RT toxicity; use of multiple toxicity scoring schemes; the multiple anatomical sites (e.g. breast, head and neck, prostate) and multiple toxicity endpoints associated with each site; the lack of consensus on the best time point for reporting toxicity; there being no standardisation of collection of additional risk factors. In addition there is a need to improve methods for incorporating dose data, including the actual dose received by surrounding normal tissues (accumulated dose or $\mathrm{D}_{\mathrm{A}}$ : see below). 


\section{What probability should be considered statistically significant in a GWAS?}

A specific issue for GWAS is the appropriate p-value considered to be statistically significant. The early literature reporting genetic association studies was littered with reports of associations that subsequently failed to replicate in independent studies. This may have been due to low frequencies of risk allele, non-causal correlations, and limited power in small studies. However, the major reason for the failure to replicate has been the use of inappropriately high $\mathrm{p}$ values, leading to false positives. Specifically, the conventional value $\mathrm{p}<0.05$ is an inappropriate threshold [32], with a $\mathrm{p}$ value $<5 \times 10^{-8}$ accepted widely as denoting genome-wide significance.

\section{Discussion}

\section{Using predictive tests of normal tissue sensitivity to alter treatment}

The overriding motivation for predictive testing is to be able to tailor RT for an individual patient to improve outcome $[76,77]$. At first sight, altering treatment to reduce toxicity in the $10 \%$ most sensitive patients would seem to be the priority. However, this applies to a minority of the population. An additional option is to also dose escalate more resistant patients, which, with a suitable division according to sensitivity, might account for $40 \%$ of patients $[56,78]$. Together, these two groups could constitute half of the patients receiving RT.

Figure 3 shows a possible approach to the alteration of treatment based on a predictive test of individual radiosensitivity. This might be based on a conventional radiosensitivity assay or on a genetic 'signature', or possibly a combination of both. Clinical implementation would also need to take into account patient- and treatment-related factors as well as physical dose, which also alter an individual's risk of toxicity (Table 1). The figure shows the population of RT patients divided into 3 groups: the most sensitive $10 \%$, the intermediate $50 \%$, and the most resistant $40 \%$ [78]. This approach would allow potential alteration in management for half of the patients receiving RT, and has the attraction of aiming to identify patients at the extremes of the distribution of sensitivity.

In terms of altered management, hyperfractionation can reduce toxicity with no risk of loss of local control or to allow for dose escalation [79]. In an EORTC head and neck study [79], hyperfractionation allowed an additional 10.5 Gy to be given, over the 70 Gy standard arm, a 
percentage difference of $15 \%$. For suitable radiosensitive patients hyperfractionation would be an ideal choice. Suitability would depend on the hyperfractionation expanding the therapeutic window, which would be contingent on the $\alpha: \beta$ ratio of the tumour being greater than that for the normal tissue. For head and neck cancer clinical evidence demonstrates that this is the case [79]; for prostate cancer the question remains open, but should be largely resolved by results from the CHHiP trial [80].

For more resistant patients, an increase in dose should be possible. This could be designed to be isotoxic, that is delivering the same risk or level of toxicity for this subpopulation as for the general population (without predictive testing), or to be hypotoxic, avoiding most or all of the toxicities seen in the general population by choosing dose escalation to a slightly less high dose. This might also provide an opportunity to add novel targeted or existing cytotoxic agents.

\section{Incorporating physical dose as a predictor of toxicity}

The conventional approach to modelling toxicity risk involves evaluation of the RT dose plan, with some consideration also given to other treatment- and patient-related factors (Table 1) $[81,82]$. Such predictive clinical models are effective, and could easily be extended to incorporate genotyping data.

A development of interest regarding use of the physical dose plan relates to the potential use of the total accumulated (delivered) dose $\left(\mathrm{D}_{\mathrm{A}}\right)$, as distinct from the planned dose [83]. In principle, this can be done by using daily image guidance studies to identify the position of critical structures, and then re-computing the dose for each daily treatment. Summated, these provide an estimate of $\mathrm{D}_{\mathrm{A}}$. A small cohort study investigating rectal $\mathrm{D}_{\mathrm{A}}$ in men receiving $\mathrm{RT}$ for prostate cancer has shown that the average position of the rectum is the same as the planning scan in most patients, but with substantial day-to-day variation [84]. This suggests that, at the population level, the RT plan is a good surrogate for $\mathrm{D}_{\mathrm{A}}$, but that for individual patients this may not be the case. In this small cohort, daily positional differences translated into differences in dose in all 10 cases studied, and were substantially higher than planned in one patient, and appreciably lower in six [85]. If the approach can be generalised, $\mathrm{D}_{\mathrm{A}}$ could usefully be added into predictive models, and could also be useful in exposing genetic variation more effectively. 


\section{Conclusions}

GWAS are at last revealing polymorphisms associated with toxicity risk, and more are likely to be identified in the near future $[57,66]$. The possibility of a genetic predictive risk 'signature' is therefore promising. In addition, the biological hypothesis-free GWAS approach is likely to increase our understanding of the underlying biology of radiation normal tissue effects. The lymphocyte apoptosis assay is currently undergoing further evaluation [43], and if validated might provide an additional rapid predictive test to screen for either hypersensitive or relatively resistant patients.

Developments in technical RT will also contribute to improved understanding of dosevolume-response relationships, and through that to better normal tissue complication probability models. Ultimately, the aim will be to develop models of individual risk, combining treatment, patient and genetic factors to achieve optimal individualisation of treatment. 


\section{Acknowledgements}

We are grateful to Prof Barry Rosenstein and Dr Jessica Scaife for helpful and stimulating discussions.

NGB is supported by the NIHR Cambridge Biomedical Research Centre. 


\section{Tables}

Table 1. Key determinants of clinical radiosensitivity.

\begin{tabular}{|c|c|c|}
\hline Physical dose factors & Treatment factors & Patient factors \\
\hline $\begin{array}{l}\text { Dose } \\
\text { Dose rate } \\
\text { Dose homogeneity } \\
\text { Treatment volume }\end{array}$ & $\begin{array}{l}\text { Surgery } \\
\text { Post-surgical cosmesis } \\
\text { Chemotherapy } \\
\text { Hormone treatment } \\
\text { Statins }\end{array}$ & $\begin{array}{l}\text { Age } \\
\text { Haemoglobin level } \\
\text { Smoking } \\
\text { Diabetes } \\
\text { Collagen vascular disease } \\
\text { Genetics }\end{array}$ \\
\hline
\end{tabular}




\section{Figures}

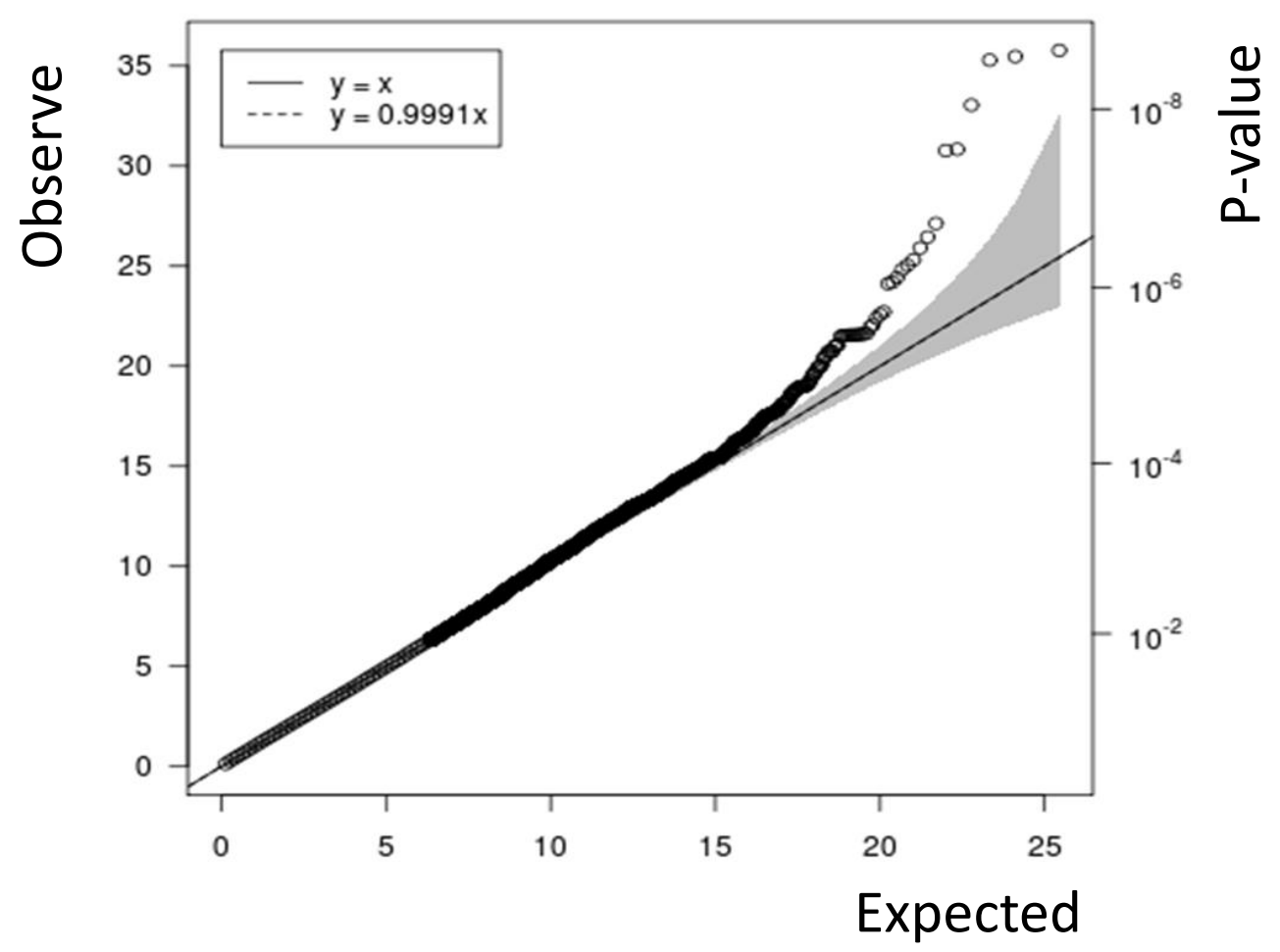

Figure 1. Example of a Q-Q plot, addressing the relationship between genetic variation and nocturnal frequency in prostate cancer patients. The Q-Q plot shows $\mathrm{P}$ values, specifically the observed $\mathrm{P}$ values versus those expected under the null hypothesis of no association between nocturnal frequency in a group of prostate patients and genotype in multivariate analysis (MVA).

In a GWAS study many hypotheses are simultaneously tested as each SNP is assessed for association with the outcome measure. It would be expected that there would be some low Pvalues obtained due to this multiple testing. A Q-Q plot is a visual means of assessing whether the observed P-values from a GWAs study deviate significantly from the P-values that would be expected from chance alone. If the distribution of p-values is as expected from chance then the points will lie along the line $y=x$. If the plot significantly deviates upwards away from the line $\mathrm{y}=\mathrm{x}$ for the lowest $10 \%$ of P-values, as shown here, this is evidence of an association between common SNPs and the toxicity endpoint measured, even if the SNPs themselves are not identified.

(Image reproduced with permission from Radiotherapy \& Oncology - requested). 


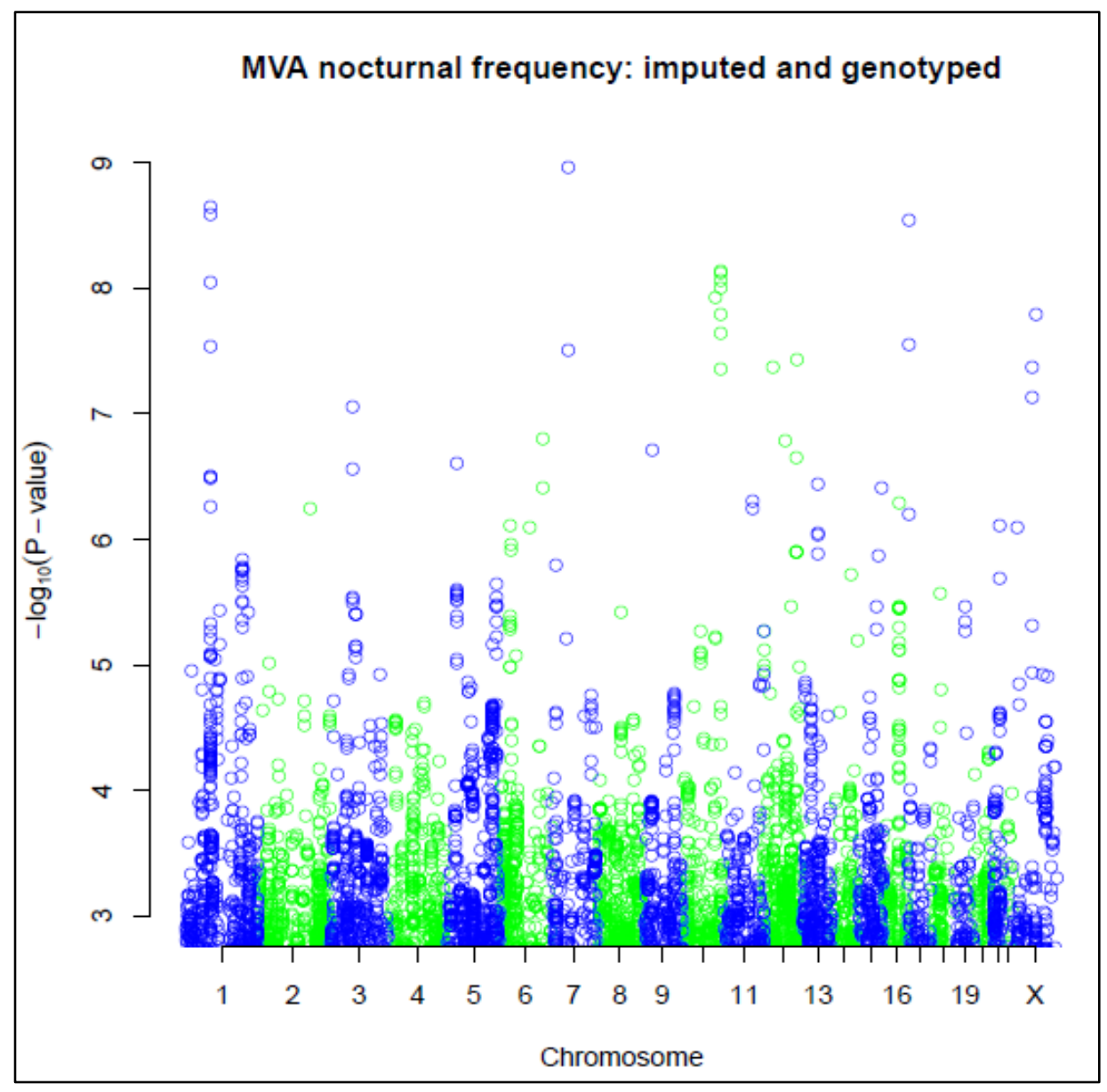

Figure 2. Example Manhattan plot from the first stage GWAS [66] showing observed $\log 10$ P-values vs. SNP position from multivariate analysis of nocturnal frequency in men treated with radiotherapy for prostate cancer. A few chromosome regions contain SNPs which show evidence of association as shown by points representing P-values $<5 \times 10^{-8}$. When the additional cohorts were included, none of the associations remained significant. 


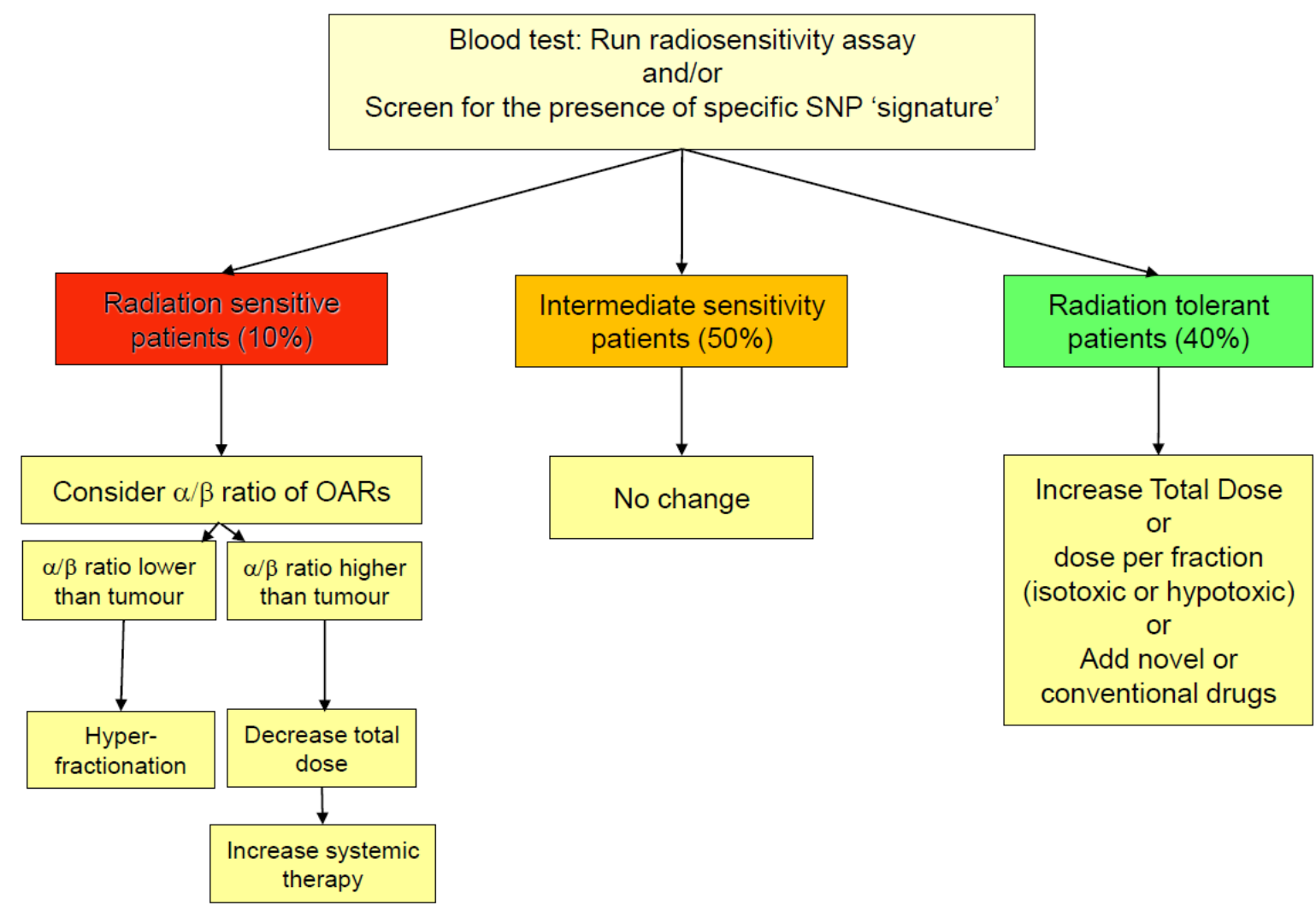

Figure 3. Schema for treatment alteration based on a predictive test of radiosensitivity. In principle this might be a radiosensitivity assay or the identification of a specific genetic 'signature'.

This shows the population of RT patients divided into 3 groups, which would allow change in management for half of the patients (sensitive 10\% plus resistant 40\%) receiving RT (see text for further details).

OAR $=$ Organ At Risk 


\section{References}

1. Bentzen SM, Heeren G, Cottier B, Slotman B, Glimelius B, Lievens Y, van den Bogaert W. Towards evidence-based guidelines for radiotherapy infrastructure and staffing needs in Europe: the ESTRO QUARTS project. Radiother Oncol. 2005; 75(3): 355-65

2. Ahmad AS, Ormiston-Smith N, Sasieni PD. Trends in the lifetime risk of developing cancer in Great Britain: comparison of risk for those born from 1930 to $1960 . \mathrm{Br} \mathrm{J}$ Cancer. 2015 Feb 3. doi: 10.1038/bjc.2014.606. [Epub ahead of print]

3. IAEA Human Health Series No. 14. Planning National Radiotherapy Services: A Practical Tool. International Atomic Energy Agency, Vienna, 2010

4. Cancer Research UK Cancer Statistics report: Incidence UK. 2014. http://publications.cancerresearchuk.org/downloads/Product/CS_REPORT_INCIDENCE. pdf (accessed 4.3.15)

5. Cahlon O, Hunt M, Zelefsky MJ. Intensity-modulated radiation therapy: supportive data for prostate cancer. Semin Radiat Oncol. 2008; 18(1): 48-57

6. Cozzarini C, Fiorino C, Di Muzio N, Alongi F, Broggi S, Cattaneo M, Montorsi F, Rigatti $\mathrm{P}$, Calandrino R, Fazio F. Significant reduction of acute toxicity following pelvic irradiation with helical tomotherapy in patients with localized prostate cancer. Radiother Oncol. 2007; 84(2): 164-70

7. Dearnaley DP, Jovic G, Syndikus I, Khoo V, Cowan RA, Graham JD, Aird EG, Bottomley D, Huddart RA, Jose CC, Matthews JH, Millar JL, Murphy C, Russell JM, Scrase CD, Parmar MK, Sydes MR. Escalated-dose versus control-dose conformal radiotherapy for prostate cancer: long-term results from the MRC RT01 randomised controlled trial. Lancet Oncol. 2014; 15(4): 464-73

8. Donovan E, Bleakley N, Denholm E, Evans P, Gothard L, Hanson J, Peckitt C, Reise S, Ross G, Sharp G, Symonds-Tayler R, Tait D, Yarnold J; Breast Technology Group. Randomised trial of standard 2D radiotherapy (RT) versus intensity-modulated radiotherapy (IMRT) in patients prescribed breast radiotherapy. Radiother Oncol. 2007; 82(3): 254-64

9. Mukesh MB, Barnett GC, Wilkinson JS, Moody AM, Wilson C, Dorling L, Chan Wah Hak C, Qian W, Twyman N, Burnet NG, Wishart GC, Coles CE. Randomized controlled trial of intensity-modulated radiotherapy for early breast cancer: 5 -year results confirm superior overall cosmesis. J Clin Oncol. 2013; 31(36): 4488-95.

10. Nutting CM, Morden JP, Harrington KJ, Urbano TG, Bhide SA, Clark C, Miles EA, Miah AB, Newbold K, Tanay M, Adab F, Jefferies SJ, Scrase C, Yap BK, A'Hern RP, Sydenham MA, Emson M, Hall E; PARSPORT trial management group. Parotid-sparing intensity-modulated versus conventional radiotherapy in head and neck cancer (PARSPORT): a phase 3 multicentre randomised controlled trial. Lancet Oncol 2011; 12(2): 127-136.

11. Pow EH, Kwong DL, McMillan AS, Wong MC, Sham JS, Leung LH, et al. Xerostomia and quality of life after intensity-modulated radiotherapy vs. conventional radiotherapy for early-stage nasopharyngeal carcinoma: initial report on a randomized controlled clinical trial. Int J, Radiat Oncol Biol Phys. 2006; 66(4): 981-991.

12. Veldeman L, Madani I, Hulstaert F, De Meerleer G, Mareel M, De Neve W. Evidence behind use of intensity-modulated radiotherapy: a systematic review of comparative clinical studies. Lancet Oncol. 2008; 9(4): 367-75

13. Zelefsky MJ, Levin EJ, Hunt M, Yamada Y, Shippy AM, Jackson A, Amols HI. Incidence of late rectal and urinary toxicities after three-dimensional conformal 
radiotherapy and intensity-modulated radiotherapy for localized prostate cancer. Int $J$ Radiat Oncol Biol Phys. 2008; 70(4): 1124-9

14. Cancer Research UK Research Strategy 2014. http://www.cancerresearchuk.org/sites/default/files/cruk_strategy.pdf (accessed 3.6.15)

15. Holthusen H. Erfahrungen über die Verträglichkeitsgrenze für Röntgenstrahlen und deren Nutzanwendung zur Verhütung von Schäden. Strahlentherapie 1936; 57: 254-269.

16. Taylor AM, Harnden DG, Arlett CF, Harcourt SA, Lehmann AR, Stevens S, Bridges BA: Ataxia telangiectasia: a human mutation with abnormal radiation sensitivity. Nature 1975; 258: 427-429.

17. Arlett CF, Harcourt SA. Survey of radiosensitivity in a variety of human cell strains. Cancer Res. 1980; 40(3): 926-32.

18. Loeffler JS, Harris JR, Dahlberg WK and Little JB. In vitro radiosensitivity of human diploid fibroblasts derived from women with unusually sensitive clinical responses to definitive radiation therapy for breast cancer. Radiat Res. 1990; 121: 227-31.

19. Plowman PN, Bridges BA, Arlett CF, Hinney A, Kingston JE. An instance of clinical radiation morbidity and cellular radiosensitivity, not associated with ataxia-telangiectasia. Br J Radiol 1990; 63: 624-628

20. Smith KC, Hahn GM, Hoppe RT and Earle JD. Radiosensitivity in vitro of human fibroblasts derived from patients with a severe skin reaction to radiation therapy. Int $J$ Radiat Oncol Biol Phys. 1980; 6: 1573-5.

21. Woods WG, Byrne TD and Kim TH. Sensitivity of cultured cells to gamma radiation in a patient exhibiting marked in vivo radiation sensitivity. Cancer. 1988; 62: 2341-5.

22. Puck TT, Marcus PI: Action of X-rays on mammalian cells. J Exp Med. 1956; 103: 653666.

23. Deschavanne PJ, Debieu D, Fertil B, Malaise EP. Re-evaluation of in vitro radiosensitivity of human fibroblasts of different genetic origins. Int J Radiat Biol. 1986; 50(2): 279-93. Erratum in: Int J Radiat Biol 1986; 50(6): 1129.

24. Little JB, Nove J, Strong LC and Nichols WW. Survival of human diploid skin fibroblasts from normal individuals after X-irradiation. Int J Radiat Biol. 1988; 54: 899-910.

25. Malaise EP, Fertil B, Deschavanne PJ, Chavaudra N and Brock WA. Initial slope of radiation survival curves is characteristic of the origin of primary and established cultures of human tumor cells and fibroblasts. Radiat Res. 1987; 111: 319-33.

26. Burnet NG, Nyman J, Turesson I, Wurm R, Yarnold JR, and Peacock JH. Improving radiotherapy cure rates by predicting normal tissue tolerance from in vitro cellular radiation sensitivity. Lancet 1992; 339: 1570-1571.

27. Burnet NG, Nyman J, Turesson I, Wurm R, Yarnold JR, Peacock JH. The relationship between cellular radiation sensitivity and tissue response to radiotherapy may provide the basis for individualising radiotherapy schedules. Radiother Oncol 1994; 33: 228-238.

28. Geara FB, Peters LJ, Ang KK, Wike JL and Brock WA. Prospective comparison of in vitro normal cell radiosensitivity and normal tissue reactions in radiotherapy patients. Int J Radiat Oncol Biol 1993; 27: 1173-1179.

29. Johansen J, Bentzen SM, Overgaard J and Overgaard M. Evidence for a positive correlation between in vitro radiosensitivity of normal human skin fibroblasts and the occurrence of subcutaneous fibrosis after radiotherapy. Int J Radiat Oncol Biol Phys 1994; 66: 407-412.

30. Peacock J, Ashton A, Bliss J, Bush C, Eady J, Jackson C, Owen R, Regan J, Yarnold J. Cellular radiosensitivity and complication risk after curative radiotherapy. Radiother Oncol. 2000; 55(2): 173-8. 
31. West CM, Davidson SE, Elyan SA, Valentine H, Roberts SA, Swindell R, Hunter RD. Lymphocyte radiosensitivity is a significant prognostic factor for morbidity in carcinoma of the cervix. Int J Radiat Oncol Biol Phys. 2001; 51(1): 10-5.

32. Health Protection Agency. Human Radiosensitivity: Report of the Independent Advisory Group on Ionising Radiation. 2013. ISBN 978-0-85951-740-9. https://www.gov.uk/government/uploads/system/uploads/attachment_data/file/333058/R CE-21_v2_for_website.pdf

33. Zhao L, Wang L, Ji W, Wang X, Zhu X, Hayman JA, Kalemkerian GP, Yang W, Brenner D, Lawrence TS, Kong FM. Elevation of plasma TGF-betal during radiation therapy predicts radiation-induced lung toxicity in patients with non-small-cell lung cancer: a combined analysis from Beijing and Michigan. Int J Radiat Oncol Biol Phys. 2009; 74(5): 1385-90.

34. Anscher MS, Murase T, Prescott DM, Marks LB, Reisenbichler H, Bentel GC, Spencer D, Sherouse G, Jirtle RL. Changes in plasma TGF beta levels during pulmonary radiotherapy as a predictor of the risk of developing radiation pneumonitis. Int J Radiat Oncol Biol Phys. 1994; 30(3): 671-6.

35. Fu XL, Huang H, Bentel G, Clough R, Jirtle RL, Kong FM, Marks LB, Anscher MS. Predicting the risk of symptomatic radiation-induced lung injury using both the physical and biologic parameters V(30) and transforming growth factor beta. Int J Radiat Oncol Biol Phys. 2001; 50(4): 899-908.

36. De Jaeger K, Seppenwoolde Y, Kampinga HH, Boersma LJ, Belderbos JS, Lebesque JV. Significance of plasma transforming growth factor-beta levels in radiotherapy for nonsmall-cell lung cancer. Int J Radiat Oncol Biol Phys. 2004; 58(5): 1378-87.

37. Marks LB, Bentzen SM, Deasy JO, Kong FM, Bradley JD, Vogelius IS, El Naqa I, Hubbs JL, Lebesque JV, Timmerman RD, Martel MK, Jackson A. Radiation dose-volume effects in the lung. Int J Radiat Oncol Biol Phys. 2010; 76(3 Suppl): S70-6.

38. Carlomagno F, Burnet NG, Turesson I, Nyman J, Peacock JH, Dunning AM, Ponder BAJ, Jackson SP. Comparison of DNA repair protein expression and activities between human fibroblast cell lines with different radiosensitivities. Int J Cancer 2000; 85(6): 845-9.

39. Badie C, Dziwura S, Raffy C, Tsigani T, Alsbeih G, Moody J, et al. Aberrant CDKN1A transcriptional response associates with abnormal sensitivity to radiation treatment. $\mathrm{Br} J$ Cancer. 2008; 98: 1845-51.

40. Henriquez Hernandez LA, Lara PC, Pinar B, Bordon E, Rodriguez Gallego C, Bilbao C, et al. Constitutive gene expression profile segregates toxicity in locally advanced breast cancer patients treated with high-dose hyperfractionated radical radiotherapy. Radiat Oncol. 2009; 4: 17.

41. Mayer C, Popanda O, Greve B, Fritz E, Illig T, Eckardt-Schupp F, et al. A radiationinduced gene expression signature as a tool to predict acute radiotherapy-induced adverse side effects. Cancer Lett. 2011; 302: 20-28.

42. Ozsahin M, Crompton NE, Gourgou S, Kramar A, Li L, Shi Y, Sozzi WJ, Zouhair A, Mirimanoff RO, Azria D. CD4 and CD8 T-lymphocyte apoptosis can predict radiationinduced late toxicity: a prospective study in 399 patients. Clin Cancer Res. 2005; 11(20): 7426-33.

43. Bourgier C, Lacombe J, Solassol J, Mange A, Pèlegrin A, Ozsahin M, Azria D. Late side-effects after curative intent radiotherapy: Identification of hypersensitive patients for personalized strategy. Crit Rev Oncol Hematol. 2015 Mar; 93(3): 312-319. Review.

44. Turesson I, Nyman J, Holmberg E, Odén A. Prognostic factors for acute and late skin reactions in radiotherapy patients. Int J Radiat Oncol Biol Phys 1996; 36:1065-75. 
45. Safwat A, Bentzen SM, Turesson I, Hendry JH. Deterministic rather than stochastic factors explain most of the variation in the expression of skin telangiectasia after radiotherapy. Int J Radiat Oncol Biol Phys. 2002; 52(1): 198-204.

46. Burnet NG, Johansen J, Turesson I, Nyman J, Peacock JH. Describing patients' normal tissue reactions: Concerning the possibility of individualising radiotherapy dose prescriptions based on potential predictive assays of normal tissue radiosensitivity. Steering Committee of the BioMed2 European Union Concerted Action Programme on the Development of Predictive Tests of Normal Tissue Response to Radiation Therapy. Int J Cancer 1998: 79; 606-613

47. Scott D (2004). Chromosomal radiosensitivity and low penetrance predisposition to cancer. Cytogenet Genome Res. 2004; 104: 365-70.

48. Roberts SA, Spreadborough AR, Bulman B, Barber JB, Evans DG, Scott D. Heritability of cellular radiosensitivity: a marker of low-penetrance predisposition genes in breast cancer? Am J Hum Genet. 1999; 65:784-94.

49. Curwen GB, Winther JF, Tawn EJ, Smart V, Whitehouse CA, Rees GS, et al. G(2) chromosomal radiosensitivity in Danish survivors of childhood and adolescent cancer and their offspring. Br J Cancer. 2005; 93: 1038-45.

50. Curwen GB, Cadwell KK, Winther JF, Tawn EJ, Rees GS, Olsen JH, et al. The heritability of G2 chromosomal radiosensitivity and its association with cancer in Danish cancer survivors and their offspring. Int J Radiat Biol. 2010; 86: 986-95.

51. Finnon P, Robertson N, Dziwura S, Raffy C, Zhang W, Ainsbury L, Kaprio J, Badie C, Bouffler S. Evidence for significant heritability of apoptotic and cell cycle responses to ionising radiation. Hum Genet. 2008; 123: 485-93.

52. Schmitz A, Bayer J, Dechamps N, Goldin L, Thomas G. Heritability of susceptibility to ionizing radiation-induced apoptosis of human lymphocyte subpopulations. Int J Radiat Oncol Biol Phys. 2007; 68:1169-77.

53. Wu X, Spitz MR, Amos CI, Lin J, Shao L, Gu J, et al. Mutagen sensitivity has high heritability: evidence from a twin study. Cancer Res. 2006; 66: 5993-6.

54. Girard PM, Kysela B, Harer CJ, Doherty AJ and Jeggo PA. Analysis of DNA ligase IV mutations found in LIG4 syndrome patients: the impact of two linked polymorphisms. Hum Mol Genet. 2004; 13: 2369-76.

55. Little JB and Nove J. Sensitivity of human diploid fibroblast cell strains from various genetic disorders to acute and protracted radiation exposure. Radiat Res. 1990; 123: 8792.

56. Barnett GC, West CML, Dunning AM, Elliott RM, Coles CE, Pharaoh PD, Burnet NG. Normal Tissue Reactions to Radiotherapy: Towards Tailoring Treatment Dose by Genotype. Nat Rev Cancer. 2009; 9(2): 134-42.

57. Kerns SL, L West CM, Andreassen CN, Barnett GC, Bentzen SM, Burnet NG, Dekker A, Ruysscher DD, Dunning A, Parliament M, Talbot C, Vega A, Rosenstein BS. Radiogenomics: the search for genetic predictors of radiotherapy response. Future Oncol. 2014 Dec; 10(15): 2391-406.

58. Alsner J, Andreassen CN, Overgaard J. Genetic markers for prediction of normal tissue toxicity after radiotherapy. Semin Radiat Oncol. 2008; 18:126-35.

59. Popanda O, Marquardt JU, Chang-Claude J and Schmezer P. Genetic variation in normal tissue toxicity induced by ionizing radiation. Mutat Res. 2009; 667: 58-69.

60. Talbot CJ, Tanteles GA, Barnett GC, Burnet NG, Chang-Claude J, Coles CE, Davidson S, Dunning AM, Mills J, Murray RJ, Popanda O, Seibold P, West CM, Yarnold JR, Symonds RP. A replicated association between polymorphisms near TNF $\alpha$ and risk for adverse reactions to radiotherapy. Br J Cancer. 2012; 107(4): 748-53. 
61. Barnett GC, Coles CE, Elliott RM, Baynes C, Luccarini C, Conroy D, Wilkinson JS, Tyrer J, Misra V, Platte R, Gulliford SL, Sydes MR, Hall E, Bentzen SM, Dearnaley DP, Burnet NG, Pharoah PD, Dunning AM, West CM. Independent validation of genes and polymorphisms reported to be associated with radiation toxicity: a prospective analysis study. Lancet Oncol. 2012; 13(1): 65-77

62. Barnett GC, Elliott RM, Alsner J, Andreassen CN, Abdelhay O, Burnet NG, ChangClaude J, Coles CE, Gutiérrez-Enríquez S, Fuentes-Raspall MJ, Alonso-Muñoz MC, Kerns S, Raabe A, Symonds RP, Seibold P, Talbot CJ, Wenz F, Wilkinson J, Yarnold J, Dunning AM, Rosenstein BS, West CM, Bentzen SM. Individual patient data metaanalysis shows no association between the SNP rs1800469 in TGFB and late radiotherapy toxicity. Radiother Oncol. 2012; 105(3): 289-95.

63. Kerns SL, Ostrer H, Stock R, Li W, Moore J, Pearlman A, Campbell C, Shao Y, Stone N, Kusnetz L, Rosenstein BS. Genome-wide association study to identify single nucleotide polymorphisms (SNPs) associated with the development of erectile dysfunction in African-American men after radiotherapy for prostate cancer. Int J Radiat Oncol Biol Phys. 2010; 78(5): 1292-300

64. Kerns SL, Stock RG, Stone NN, Blacksburg SR, Rath L, Vega A, Fachal L, GómezCaamaño A, De Ruysscher D, Lammering G, Parliament M, Blackshaw M, Sia M, Cesaretti J, Terk M, Hixson R, Rosenstein BS, Ostrer H. Genome-wide association study identifies a region on chromosome 11q14.3 associated with late rectal bleeding following radiation therapy for prostate cancer. Radiother Oncol. 2013; 107(3): 372-6

65. Barnett GC, West CML, Coles CE, Pharoah PDP, Talbot CJ, Elliott RM, Tanteles GA, Symonds RP, Wilkinson J, Dunning AM, Burnet NG, Bentzen SM. Standardized Total Average Toxicity (STAT) Score: A scale- and grade-independent measure of late radiotherapy toxicity to facilitate pooling of data from different studies. Int $J$ Radiat Oncol Biol Phys. 2012; 82(3): 1065-74.

66. Barnett GC, Thompson D, Fachal L, Kerns S, Talbot C, Elliott RM, Dorling L, Coles CE, Dearnaley DP, Rosenstein BS, Vega A, Symonds P, Yarnold J, Baynes C, Michailidou K, Dennis J, Tyrer JP, Wilkinson JS, Gómez-Caamaño A, Tanteles GA, Platte R, Mayes R, Conroy D, Maranian M, Luccarini C, Gulliford SL, Sydes MR, Hall E, Haviland J, Misra V, Titley J, Bentzen SM, Pharoah PD, Burnet NG, Dunning AM, West CM. A genome wide association study (GWAS) providing evidence of an association between common genetic variants and late radiotherapy toxicity. Radiother Oncol. 2014 May; 111(2): 17885.

67. Fachal L, Gómez-Caamaño A, Barnett GC, Peleteiro P, Carballo A, Calvo-Crespo P, Kerns SL, Sánchez-García M, Lobato-Busto R, Dorling L, Elliott RM, Dearnaley D, Sydes MR, Hall E, Burnet NG, Carracedo A, Rosenstein BS, West CML, Dunning AM, Vega A. A three-stage genome-wide association study identifies a susceptibility locus for late radiotherapy toxicity at 2q24.1. Nature Genetics 2014 Aug;46(8):891-4.

68. Andreassen CN, Alsner J: Genetic variants and normal tissue toxicity after radiotherapy: a systematic review. Radiother Oncol. 2009; 92: 299-309.

69. West C, Rosenstein BS, Alsner J, Azria D, Barnett G, Begg A, Bentzen S, Burnet N, Chang-Claude J, Chuang E et al: Establishment of a Radiogenomics Consortium. Int J Radiat Oncol Biol Phys. 2010; 76:1295-1296.

70. Burnet NG, Elliott RM, Dunning A, West CM. Radiosensitivity, radiogenomics and RAPPER. Clin Oncol (R Coll Radiol). 2006; 18:525-8.

71. Ho AY, Atencio DP, Peters S, Stock RG, Formenti SC, Cesaretti JA, Green S, Haffty B, Drumea K, Leitzin L et al: Genetic predictors of adverse radiotherapy effects: the GenePARE project. Int J Radiat Oncol Biol Phys. 2006; 65: 646-655. 
72. Suga T, Ishikawa A, Kohda M, Otsuka Y, Yamada S, Yamamoto N, Shibamoto Y, Ogawa Y, Nomura K, Sho K et al: Haplotype-based analysis of genes associated with risk of adverse skin reactions after radiotherapy in breast cancer patients. Int J Radiat Oncol Biol Phys. 2007; 69: 685-693.

73. Fachal L, Gómez-Caamaño A, Peleteiro P, Carballo A, Calvo-Crespo P, Sánchez-García M, Lobato-Busto R, Carracedo A, Vega A. Association of a XRCC3 polymorphism and rectum mean dose with the risk of acute radio-induced gastrointestinal toxicity in prostate cancer patients. Radiother Oncol. 2012; 105(3): 321-8.

74. Kerns SL, Ruysscher DD, Andreassen CN, et al. STROGAR - STrengthening the Reporting Of Genetic Association studies in Radiogenomics. Radiother Oncol. 2014; 110(1): 182-8

75. Mavaddat N, Pharoah PD, Michailidou K, Tyrer J, Brook MN, Bolla MK et al. Prediction of breast cancer risk based on profiling with common genetic variants. $J$ Nat Cancer Inst. 2015 Apr 8; 107(5)

76. West CM, Barnett GC. Genetics and genomics of radiotherapy toxicity: towards prediction. Genome Med. 2011; 3(8): 52.

77. West CM, Dunning AM, Rosenstein BS. Genome-wide association studies and prediction of normal tissue toxicity. Semin Radiat Oncol 2012; 22:91-9.

78. Burnet NG, Wurm R, Nyman J, Peacock JH. Normal tissue radiosensitivity - how important is it? Clin Oncol 1996; 8: 25-34.

79. Horiot JC, Le Fur R, N'Guyen T, Chenal C, Schraub S, Alfonsi S, Gardani G, Van Den Bogaert W, Danczak S, Bolla M, et al. Hyperfractionation versus conventional fractionation in oropharyngeal carcinoma: final analysis of a randomized trial of the EORTC cooperative group of radiotherapy. Radiother Oncol. 1992; 25(4): 231-41.

80. Khoo VS, Dearnaley DP. Question of dose, fractionation and technique: ingredients for testing hypofractionation in prostate cancer--the CHHiP trial. Clin Oncol (R Coll Radiol). 2008; 20(1): 12-4

81. Valdagni R, Rancati T, Ghilotti M, Cozzarini C, Vavassori V, Fellin G, Fiorino C, Girelli G, Barra S, Zaffaroni N, Pierotti MA, Gariboldi M. To bleed or not to bleed. A prediction based on individual gene profiling combined with dose-volume histogram shapes in prostate cancer patients undergoing three-dimensional conformal radiation therapy. Int J Radiat Oncol Biol Phys. 2009; 74(5): 1431-40.

82. Dehing-Oberije C, De Ruysscher D, Petit S, Van Meerbeeck J, Vandecasteele K, De Neve W, Dingemans AM, El Naqa I, Deasy J, Bradley J et al: Development, external validation and clinical usefulness of a practical prediction model for radiation-induced dysphagia in lung cancer patients. Radiother Oncol 2010, 97:455-461.

83. Jaffray DA, Lindsay PE, Brock KK, Deasy JO, Tomé WA. Accurate accumulation of dose for improved understanding of radiation effects in normal tissue. Int J Radiat Oncol Biol Phys. 2010; 76(3 Suppl): S135-9

84. Scaife JE, Harrison K, Romanchikova M, Parker, MA, Sutcliffe MPF, Bond S, Thomas SJ, Freeman S, Jena R, Bates AM, Burnet NG. Random variation in rectal position during radiotherapy for prostate cancer is up to three times higher than that predicted from prostate motion. Brit J Radiol. 2014 Oct;87(1042):20140343.

85. Scaife J, Harrison K, Romanchikova M, Thomas S, Jena R, Burnet NG. Accumulated Dose Volumes to the Rectum are Different from those Planned in Approximately 80\% of Patients Treated with Helical TomoTherapy for Prostate Cancer. Clin Oncol. 2015; 27(3): e3-e4 